\title{
Characterizing Spatial-Temporal Variations in Vegetation Phenology over the North-South Transect of Northeast Asia Based upon the MERIS Terrestrial Chlorophyll Index
}

\author{
Jiaxin Jin $^{1}$, Hong Jiang ${ }^{1,2, *}$, Xiuying Zhang ${ }^{1}$, and Ying Wang ${ }^{1}$ \\ ${ }^{1}$ International Institute for Earth System Science, Nanjing University, Nanjing, China \\ ${ }^{2}$ State Key Laboratory of Subtropical Forest Science and Zhejiang Provincial Key Laboratory of Carbon Cycling \\ in Forest Ecosystems and Carbon Sequestration, Zhejiang Agriculture and Forestry University, Hangzhou, China
}

Received 20 September 2011, accepted 12 March 2012

\begin{abstract}
This study attempted to establish a broad regional phenological pattern for Northeast Asia using time-series data of the satellite measured index of terrestrial chlorophyll content (MERIS Terrestrial Chlorophyll Index) from 2003 to 2007. A suite of phenological variables were extracted from 4 integral seasons of time-series Medium Resolution Imaging Spectrometer (MERIS) Terrestrial Chlorophyll Index (MTCI) of World Wildlife Fund (WWF) ecoregions smoothed by an asymmetric Gaussian model. In this study, spatial variation with latitude was observed for the chlorophyll content and phenological variables for natural vegetation across north-south transect of northeast Asia (NSTNEA). The onset of greenness for most ecoregions followed a latitudinal pattern with an earlier onset of greenness at lower latitudes. In general, the length of growing season was higher at lower latitudes. For forests in NSTNEA, the average maximum MTCI value and range of MTCI value at lower latitudes were significantly larger than that at higher latitudes during the study period. In addition, the cumulative CV showed a declining trend with an increase in latitude overall. Our findings suggest that although precipitation plays a promoting role, temperature is still the dominant factor in vegetation phenological period at high latitudes.
\end{abstract}

Key words: Phenology, Chlorophyll index, Time-series, Terrestrial transect, Northeast Asia, Satellite data, Ecosystem succession Citation: Jin, J., H. Jiang, X. Zhang, and Y. Wang, 2012: Characterizing spatial-temporal variations in vegetation phenology over the north-south transect of northeast Asia based upon the MERIS Terrestrial Chlorophyll Index. Terr. Atmos. Ocean. Sci., 23, 413-424, doi: 10.3319/TAO.2012.03.12.01(A)

\section{INTRODUCTION}

Substantial climate warming has occurred during the 20th century, especially during the last 30 years of the century (IPCC 2001a, b). It has also been observed that over the past century temperatures have increased to a greater extent in the Arctic and sub-Arctic regions (Hinzman et al. 2005). Two regions in the Northern Hemisphere, the western part of the North America and Siberia, have been the most affected by the recent warming (Groisman et al. 2006). As high latitude ecosystems contain ca. $40 \%$ of the world's soil carbon inventory that is potentially reactive in response to near-term climate change (McGuire et al. 1997), functional and structural changes in high latitude ecosystems have the potential to influence the carbon exchange with the atmosphere (McGuire et al. 2000). Responses of high latitude

\footnotetext{
* Corresponding author

E-mail:jianghong_china@hotmail.com
}

ecosystems to global change have the potential to influence the water and energy exchange with the atmosphere in several ways (Chapin III et al. 2000). It is clear that the responses of high latitude ecosystems to global change involve complex interactions among environmental variables, vegetation distribution, carbon dynamics, and water and energy exchange (Hofgaard 1997).

Long-term data indicate that the recent rapid climate change and anomalous climate of the past half-century are already affecting the physiology, distribution, and phenology of some species as well as a wide variety of organisms (Edwards and Richardson 2004). There is a growing consensus that arctic regions will experience marked changes in precipitation, temperature, and the timing of seasonal climate events (Bradley et al. 1993). Arctic vegetation appears to be particularly sensitive to climate changes (Epstein et al. 2000). Seasonal characteristics of plants, such as emergence 
and senescence, are closely related to characteristics of the lower atmosphere, including the annual cycle of weather pattern shifts, and temperature and humidity characteristics (Reed et al. 1994). Therefore, variations in phenological events may signal important inter-annual climatic or even global environmental change. Remote sensing of vegetation involves an implicit link to vegetation phenology. Spectraltemporal profiles of remotely sensed vegetation index values have been used for identifying the occurrence of significant phenological events. It is recognized that a vegetation index time-series carries useful information about seasonal vegetation development and that this information will aid analyses of the functional and structural characteristics of the land cover (Jönsson and Eklundh 2002). Temporal vegetation information such as moisture and carbon dioxide on a global scale is important for strengthening our current knowledge concerning global cycles of matter (Rosenqvist et al. 2000). In addition, because remotely sensed data which comprise the vegetation index is gathered almost daily and covers large areas, it has been widely used for monitoring spatial gradients and the intra-seasonal dynamics of vegetation, especially in large and remote regions (Gutman et al. 1994; Jia et al. 2002).

The realization that human-induced environmental changes often have impacts at continental and global scales has prompted the development of new ways to address large-scale and complex research problems. These new research approaches need to deal with an unprecedented level of integration and coordination of multiple disciplines and data streams generated by different scientific communities, institutions and countries (Canadell et al. 2000). In the early 1990s, the Global Change and Terrestrial Ecosystems (GCTE) project of the International Geosphere-Biosphere Programme (IGBP) developed the approach using terrestrial transects for global change research as a way to address large spatial phenomena with both regional and global implications (Koch et al. 1995). The IGBP Terrestrial Transects are a set of integrated global change studies consisting of distributed observational studies and manipulative experiments coupled with modeling and synthesis activities organized along existing gradients of underlying global change parameters, such as temperature, precipitation and land use (Koch et al. 1995). The IGBP Terrestrial Transects were established in critical regions of the world, in order to cover most environmental conditions and biomes/ecotones, with special attention to highly sensitive regions with strong feedback with regard to global change. The transects are currently used along with other IGBP research approaches in order to gain the necessary mechanistic information and appropriate spatial and temporal coverage to deal with specific regional, continental or global scale analyses (Canadell et al. 2002). In Northeast Asia, there were four IGBP terrestrial transects, including the North East Chinese Transect (NETC), the North-South Transect of Eastern Chi- na (NSTEC), the Central Siberia Transect (CST) and the Far East Siberia Transect (FEST). Over the last 10 years, many targeted studies, including transect gradient analyses, ecosystem response and feedback, net primary productivity model simulation, etc., were reported in these transects, while transnational studies on global changes were rarely carried out for various reasons.

Recently, major studies on remotely-sensed vegetation phenology curves are usually produced in the Normal Difference Vegetation Index (NDVI). However, because of the limitations of the NDVI, such as notoriously noisy saturation at high levels of vegetation biomass and chlorophyll concentration (Huete et al. 2002; Mutanga et al. 2004) and an unexplained deviation in phenology curves with changing atmospheric conditions (Goward et al. 1991) extracting reliable phenological information is difficult. In this regard, the Medium Resolution Imaging Spectrometer (MERIS) Terrestrial Chlorophyll Index (MTCI) would be more appropriate than the NDVI (Jeganathan et al. 2010). The MTCI is directly related to canopy chlorophyll content, which is a function of chlorophyll concentration and leaf area index (LAI). Dash et al. (2008) determined the signalto-noise ratio (SNR) for the NDVI and MTCI time series for eight land cover types using iterative polynomial fitting and discrete Fourier transformation. The findings showed that the SNR for MTCI curves were significantly higher than for the NDVI curves and this difference was the largest for high green biomass areas. In addition, the two methods of SNR calculation produced different results for the NDVI but not the MTCI, thus suggesting that MTCI was less affected by sensor and environmental noise. In this study, defining a North-South transect in Northeast Asia (NSTNEA) which considered the combined temperature and precipitation conditions as study areas, the present work extracted a chlorophyll index of terrestrial eco-regions in the transect using MTCI from June 2002 to June 2007. A smoothing algorithm based on nonlinear least squares fits of Asymmetric Gaussian model (AGM) function directly to the time-series was applied to the MTCI dataset to minimize the effects of anomalous values. A suite of 8 phonological metrics were derived from 4 integral growth cycle of time-series MTCI data for each ecoregion. The specific objectives in this study are: (i) to describe the spatio-temporal variations in vegetation chlorophyll at middle and high latitudes of Northeast Asia; (ii) to evaluate the potential of MTCI to extract phenological variables and monitor change in phonological variables at high latitudes; and (iii) to reveal the phenological differences and variations of ecoregions resulting from temperature and precipitation gradients in Northeast Asia.

\section{STUDY AREA}

The climate of Northeast Asia (China, Russia, and Mongolia) has undergone significant changes over the last 
30 years (Chase et al. 2000), especially in the region around Lake Baikal (Yu et al. 2003). Furthermore, ecosystems in high latitudes appear to be particularly sensitive to climate changes with strong feedback. Changes in ecosystem dynamics for this region can directly affect land use, biodiversity, and human socioeconomics. Therefore, it is very necessary to set a transect which not only meets the requirements of IGBP Terrestrial Transects but also is beneficial to scientific communities of different countries. Considering the above, the defined study area (Fig. 1) in this paper, the North-South Transect of Northeast Asia (NSTNEA), ranges from 32 to $78^{\circ} \mathrm{N}$ and 105 to $118^{\circ} \mathrm{E}$. The transect centers on Lake Baikal, extending southward to Inner Mongolia in China and northward to the polar region. It represents a combined temperature and precipitation gradient in Northeast Asia. The major global change gradient is temperature (Fig. 2a) ranging from $15^{\circ} \mathrm{C}$ in the south to $-15^{\circ} \mathrm{C}$ in the north for average annual temperature. The annual precipitation (Fig. 2b) also shows a reduced gradient with an increase in latitude overall, but at $44^{\circ} \mathrm{N}$ there was a low value where the Alashan Plateau semi-desert locates. The precipitation recovers till about $58^{\circ} \mathrm{N}$, then it showed a gradual decrease with increasing latitude. The vegetation types along the transect vary gradually from broad leaf forests, agricultural fields, and desert steppes in the south to boreal forest, conifer-deciduous broad leaf mixed forests, conifer forests and steppe and tundra in the north.

According to the Terrestrial Ecoregions from the World Wildlife Fund (WWF) (www.worldwildlife.org), there are 17 ecoregions (Fig. 1 and Table 1) in the transect, and the spatial distribution and latitude range are shown in Fig. 1. In this study, we selected this ecoregion as the research objective because it has consistent environmental conditions and vegetation types and represents the features of a dominant ecosystem. Arranged by latitude, the characteristics of ecoregions could reflect the diversity driven by climatic factors based on the temperature and precipitation gradient of the transect.

(a)

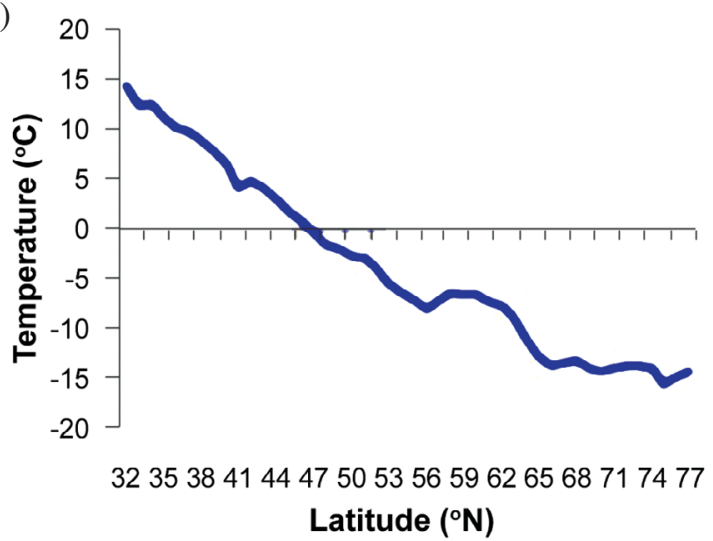

\section{MATERIAL AND METHOD}

\subsection{MTCI}

The remote sensing vegetation index source used for this research was 8-day temporal composites of the Medium Resolution Imaging Spectrometer (MERIS) Terrestrial

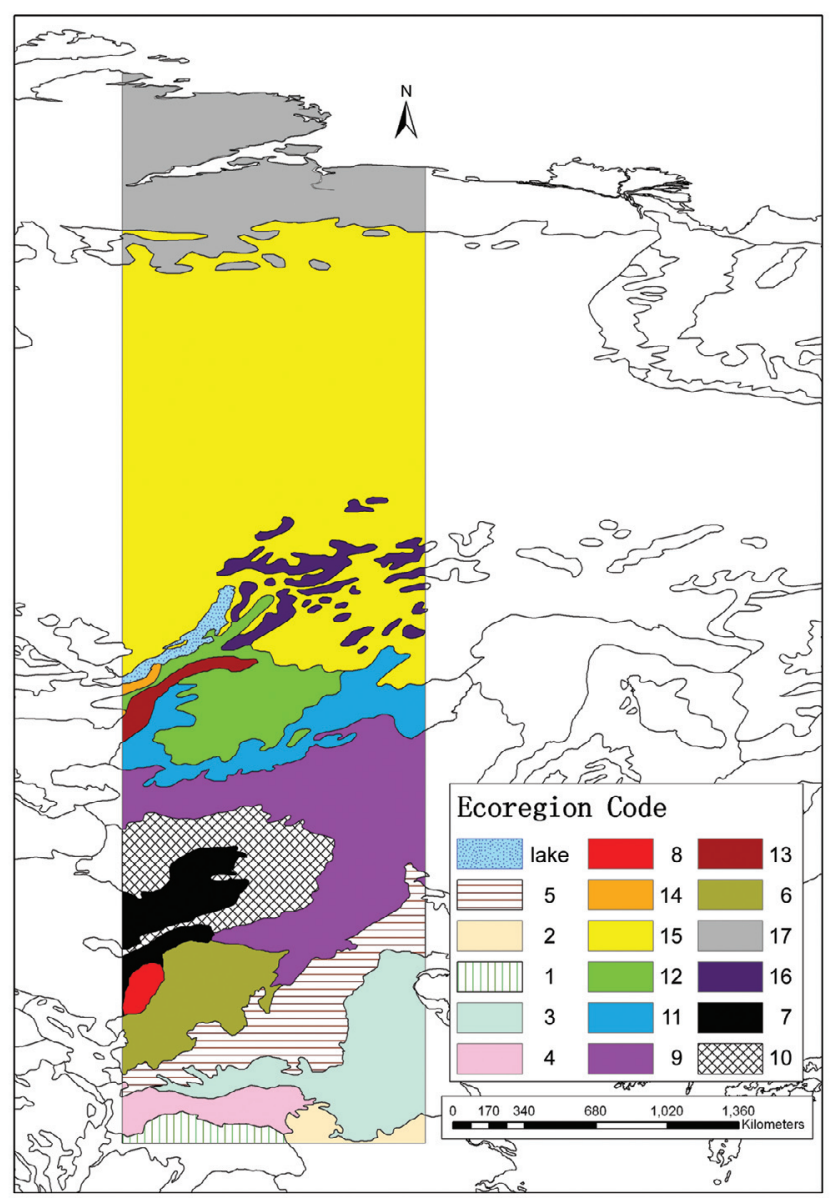

Fig. 1. The WWF ecoregions in the North-South Transect of Northeast Asia.

Fig. 2. Latitudinal variations in (a) average annual temperature and (b) total precipitation across the NSTNEA. 
Table 1. WWF ecoregions in NSTNEA.

\begin{tabular}{ccl}
\hline Num & Eco_Code & \multicolumn{1}{c}{ Eco_Name } \\
\hline 1 & PA0417 & Daba Mountains evergreen forests \\
2 & PA0415 & Changjiang Plain evergreen forests \\
3 & PA0424 & Huang He Plain mixed forests \\
4 & PA0434 & Qin Ling Mountains deciduous forests \\
5 & PA0411 & Central China loess plateau mixed forests \\
6 & PA1013 & Ordos Plateau steppe \\
7 & PA1302 & Alashan Plateau semi-desert \\
8 & PA0508 & Helanshan montane conifer forests \\
9 & PA0813 & Mongolian-Manchurian grassland \\
10 & PA1314 & Eastern Gobi desert steppe \\
11 & PA0804 & Daurian forest steppe \\
12 & PA0609 & Trans-Baikal conifer forests \\
13 & PA0816 & Selenge-Orkhon forest steppe \\
14 & PA0519 & Sayan montane conifer forests \\
15 & PA0601 & East Siberian taiga \\
16 & PA1112 & Trans-Baikal Bald Mountain tundra \\
17 & PA1111 & Taimyr-Central Siberian tundra \\
\hline & &
\end{tabular}

Chlorophyll Index (MTCI). MERIS, one of the payloads on Envisat, has fine spectral resolution (Curran et al. 2005), moderate spatial resolution $(300 \mathrm{~m}$ and $1 \mathrm{~km})$ and a 3-day repeat cycle. These make MERIS a potentially valuable sensor for the measurement and monitoring of terrestrial environments at regional to global scales. The MTCI is a ratio of the difference in reflectance between band 10 (750 - $757.5 \mathrm{~nm})$ and band $9(703.75-713.75 \mathrm{~nm})$ and the difference in reflectance between band 9 and band 8 (614.5 $622 \mathrm{~nm}$ ) of the MERIS standard band setting

MTCI $=\frac{R_{\text {Band10 }}-R_{\text {Band9 }}}{R_{\text {Band9 }}-R_{\text {Band8 }}}=\frac{R_{753.75}-R_{708.75}}{R_{708.75}-R_{681.25}}$

where $\mathrm{R}_{753.75}, \mathrm{R}_{708.75}, \mathrm{R}_{681.25}$ are reflectance in the centre wavelengths of band 8,9 and 10 in the MERIS standard band setting (Dash et al. 2007, 2010).

As a standard level-2 product of the European Space Agency, the MTCI effectively combines information on the LAI and chlorophyll concentration of leaves to produce an image of chlorophyll content which is simple to calculate and is sensitive to a wide range of values of chlorophyll contents. Eight day composites of MERIS MTCI data at $4.6 \mathrm{~km}$ spatial resolution from 2003 to 2007 were obtained from the NERC Earth Observation Data Centre (NEODC) website (http://www.neodc.rl.ac.uk). MTCI data were composited using an arithmetic mean, which is less sensitive to temporal biases compared to the widely used maximum value compositing, and, with an optimised cloud mask, it can pro- duce images with greater spatial and spectral consistency than other techniques (Jeganathan et al. 2010). The MTCI has been validated for several different species (Zhang et al. 2008), and the results all show a large positive correlation between MTCI and chlorophyll content. The MTCI has now been used in applications of varying scope such as modeling forest productivity (Berberoglu et al. 2007), estimating nitrogen concentration (España-Boquera et al. 2006) and inferring salt stress (Curran et al. 2007).

\subsection{Asymmetric Gaussian Model}

In this paper, we follow the notation of Jönsson and Eklundh (2004) to extract seasonality information from noisy satellite sensor data. This method is based on nonlinear least squares fits of Asymmetric Gaussian model (AGM) functions to the MTCI time-series. Simple local nonlinear model functions are fitted to sets of data points $\left(\mathrm{t}_{\mathrm{i}}, \mathrm{I}_{\mathrm{i}}\right), \mathrm{I}=\mathrm{n}_{1}, \ldots, \mathrm{n}_{2}$, where $t_{i}$ is time and $I_{i}$ is MTCI. They are used to build global functions which correctly describe the MTCI variation of full growing seasons. In this method local model functions are fitted to data in intervals around maxima and minima in the time-series. The local model functions have the general form

$\mathrm{f}(\mathrm{t}) \equiv \mathrm{f}(\mathrm{t} ; \mathrm{c}, \mathrm{x})=\mathrm{c}_{1}+\mathrm{c}_{2} \mathrm{~g}(\mathrm{t} ; \mathrm{x})$

where the linear parameters $\mathrm{c}=\left(\mathrm{c}_{1}, \mathrm{c}_{2}\right)$ determine the base level and the amplitude. The non-linear parameters $\mathrm{x}=\left(\mathrm{x}_{1}\right.$, $\left.\mathrm{x}_{2}, \ldots, \mathrm{x}_{\mathrm{p}}\right)$ determine the shape of the basis function $\mathrm{g}(\mathrm{t} ; \mathrm{x})$. In this case the basis function is a Gaussian type of function.

$g\left(t ; x_{1}, x_{2}, \ldots, x_{5}\right)= \begin{cases}\exp \left[-\left(\frac{t-x_{1}}{x_{2}}\right)^{x_{3}}\right] & \text { if } t>x_{1} \\ \exp \left[-\left(\frac{x_{1}-t}{x_{4}}\right)^{x_{5}}\right] & \text { if } t<x_{1}\end{cases}$

For this function $x_{1}$ determines the position of the maximum or minimum with respect to the independent time variable $\mathrm{t}$, while $\mathrm{x}_{2}$ and $\mathrm{x}_{3}$ determine the width and flatness of the right function half. Similarly, $\mathrm{x}_{4}$ and $\mathrm{x}_{5}$ determine the width and flatness of the left half. In order to ensure smooth shapes of the model functions consistent with what is observed for data, the parameters $\mathrm{x}_{2}, \ldots, \mathrm{x}_{5}$ are restricted in range. The local model functions are well suited for describing the shape of the scaled MTCI time-series in overlapping intervals around maxima and minima. If we select a set of data points $\left(\mathrm{t}_{\mathrm{i}}, \mathrm{I}_{\mathrm{i}}\right), \mathrm{i}=\mathrm{n}_{1}, \ldots, \mathrm{n}_{2}$ in an interval around a maximum or a minimum, the parameters $\mathrm{c}_{1}, \mathrm{c}_{2}$, and $\mathrm{x}_{1}, \ldots, \mathrm{x}_{5}$ are obtained by minimizing the merit function

$\chi^{2}=\sum_{i=n_{1}}^{n_{2}}\left[\frac{f\left(t_{i} ; c_{1}, c_{2}, x_{1}, \ldots, x_{5}\right)-I_{i}}{\sigma_{i}}\right]^{2}$ 
where $\sigma_{\mathrm{i}}$ is the measurement uncertainty of the $i$ th data point, they are all set to the constant value $\sigma_{\mathrm{i}}=1$ in this study.

Denoting the local functions describing the time-series in intervals around the left minimum, the central maximum and the right minimum by $\mathrm{f}_{\mathrm{L}}(\mathrm{t}), \mathrm{f}_{\mathrm{C}}(\mathrm{t})$, and $\mathrm{f}_{\mathrm{R}}(\mathrm{t})$, the global function $F(t)$, that correctly models the time-series in the full interval $\left(t_{L}, t_{R}\right)$, is

$\mathrm{F}(\mathrm{t})= \begin{cases}\alpha(\mathrm{t}) \mathrm{f}_{\mathrm{L}}(\mathrm{t})+[1-\alpha(\mathrm{t})] \mathrm{f}_{\mathrm{C}}(\mathrm{t}) & \mathrm{t}_{\mathrm{L}}<\mathrm{t}<\mathrm{t}_{\mathrm{C}} \\ \beta(\mathrm{t}) \mathrm{f}_{\mathrm{C}}(\mathrm{t})+[1-\beta(\mathrm{t})] \mathrm{f}_{\mathrm{R}}(\mathrm{t}) & \mathrm{t}_{\mathrm{C}}<\mathrm{t}<\mathrm{t}_{\mathrm{L}}\end{cases}$

Here $\alpha(t)$ and $\beta(t)$ are cut-off functions that in small intervals around $\left(t_{L}+t_{C}\right) / 2$ and $\left(t_{C}+t_{R}\right) / 2$, respectively, smoothly drop from 1 to 0 . Loosely speaking, the global function $F(t)$ assumes the character of $f_{L}(t), f_{C}(t)$, and $f_{R}(t)$ in, respectively, the left, central and right part of the interval $\left(t_{L}, t_{R}\right)$. The merging of local functions to a global function is a key feature of the method. It increases the flexibility and allows the fitted function to follow a complex behavior of the time-series (Jönsson and Eklundh 2002). Taking ecoregion PA1302 (Alashan Plateau semi-desert) as an example, the effect of data smoothing on the MTCI time-series is illustrated in Fig. 3. It can be seen in the top-most plot that there were significant anomalous or missing data due to cloud cover. These were smoothed by the models. The AGM was able to capture the broad phonological pattern and major variation during a full growing season.

\subsection{Phenological Metrics}

The phenological metrics were extracted from the smoothed MTCI data for ecoregions in the NSTNEA, in- cluding time of onset of greenness $(\mathrm{OnP})$, time of the end of greenness (EndP), duration of greenness (DurP), time of maximum MTCI (MaxP), maximum MTCI value (MaxV), range of MTCI values (RanV), duration of greenup (DurUp) and duration of senescence (DurDn) (Reed et al. 1994).

The first derivative refers to the change in MTCI value from its immediate previous neighbor. If composite period $t$ is the OnP, the slope angle must be positive and represents the maximum change in the MTCI. Hence, the OnP was defined as the maximum first derivative value over the smoothed MTCI curves (Fig. 4). The EndP was determined in a similar manner, but the minimum first derivative was applied in reverse chronological order (Fig. 4). The DurP, measured in eight day composites, was derived by subtracting the time of onset of greenness from the time of the end of season (Fig. 4). The smoothed data were used to identify the $\mathrm{MaxP}$ and $\mathrm{Max} \mathrm{V}$ for the growing season. After establishing the metrics for the maximum MTCI value, the RanV was computed by subtracting the average of the left and right minimum MTCI value from the maximum MTCI value in each growing season (Fig. 4). The DurUp and DurDn were computed as a composite period from onset to the maximum and from the maximum to the end, respectively (Fig. 4).

\section{RESULTS}

\subsection{The Spatio-Temporal Variation of Chlorophyll in NSTNEA}

Figure 5a represents the spatio-temporal variations in multi-year monthly mean MTCI from 2002 to 2007 across the NSTNEA. The figure suggests that there are significant seasonal pattern and difference in chlorophyll content for different ecoregions across Northeast Asia. In NSTNEA,

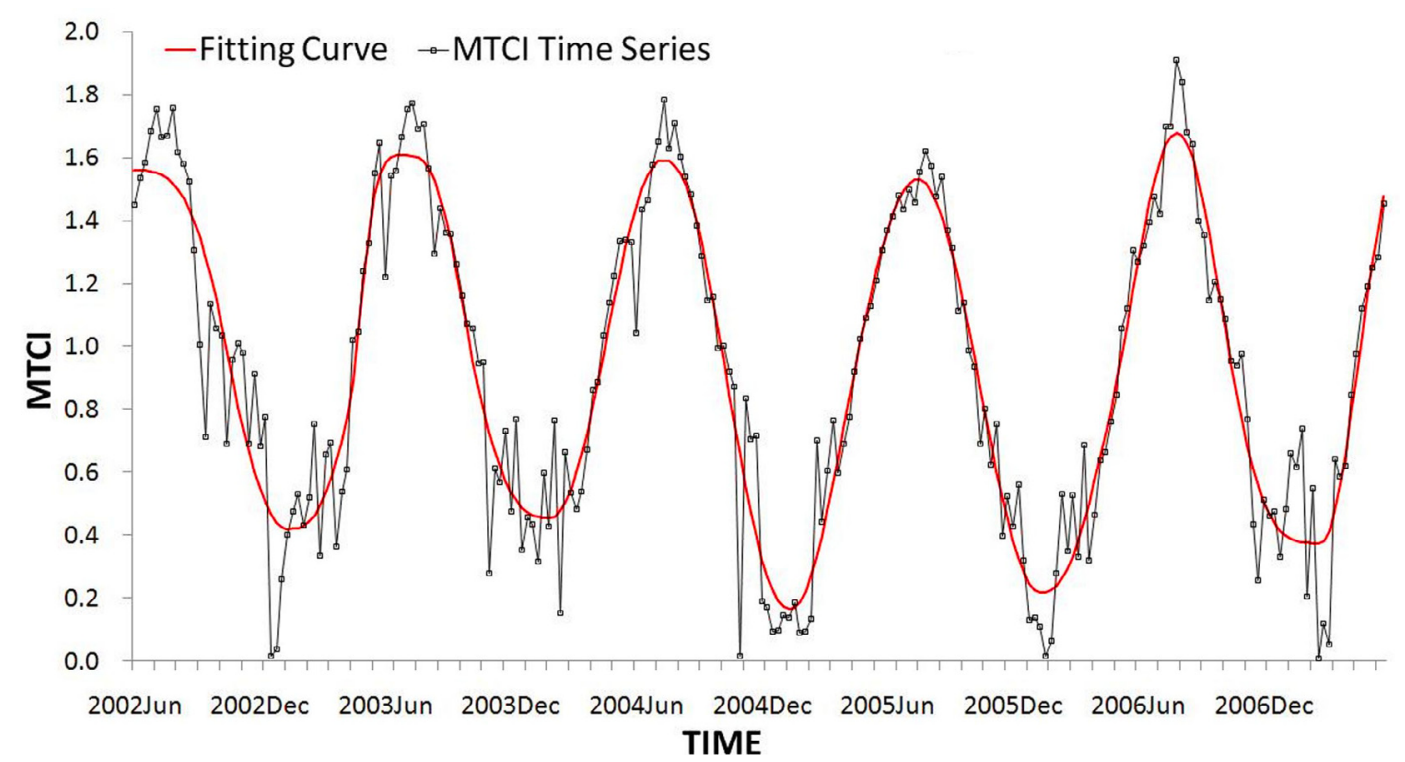

Fig. 3. Effect of smoothing on the MTCI time-series data for PA1302 (Alashan Plateau semi-desert). 


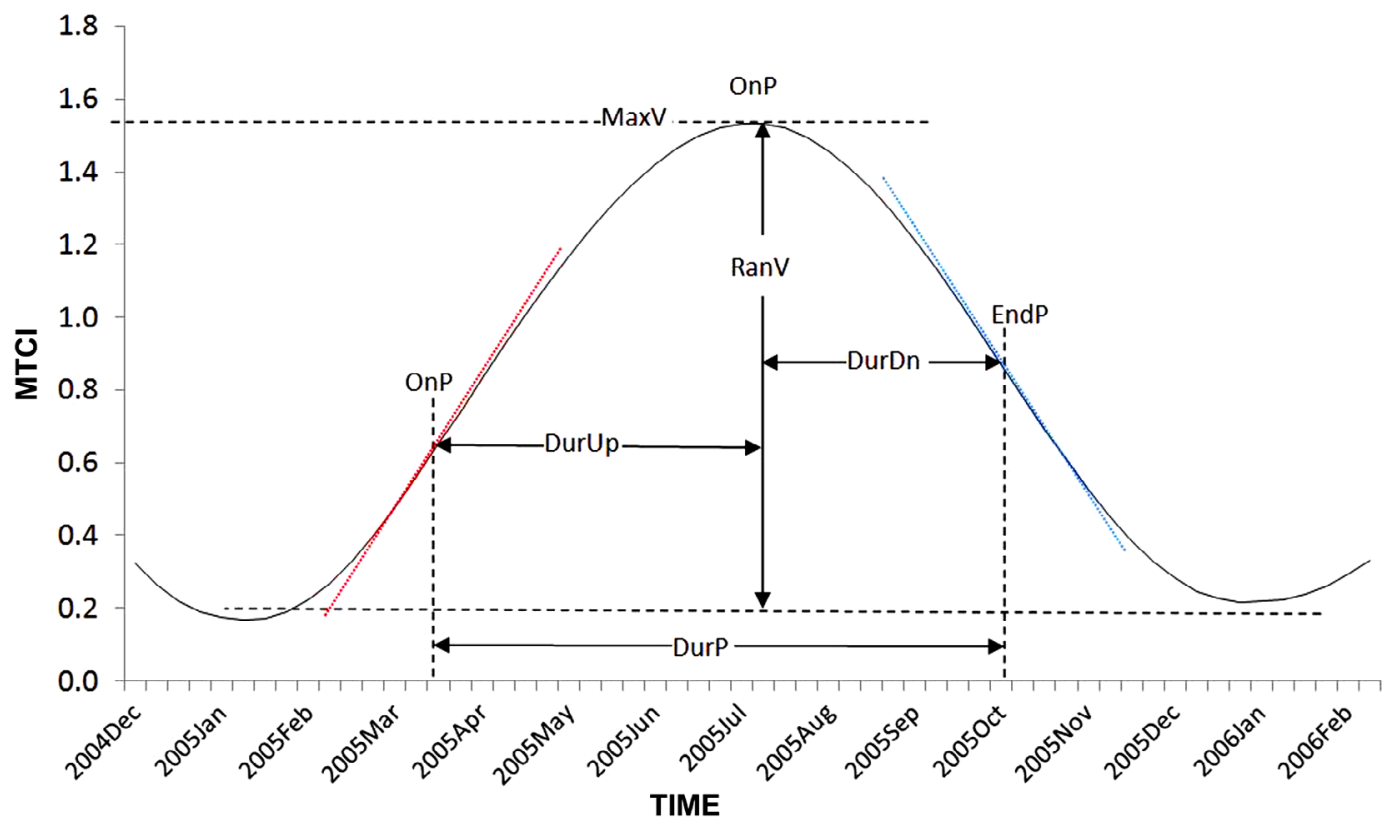

Fig. 4. Schematic representation of the phonological variables extracted in this study.

(a)
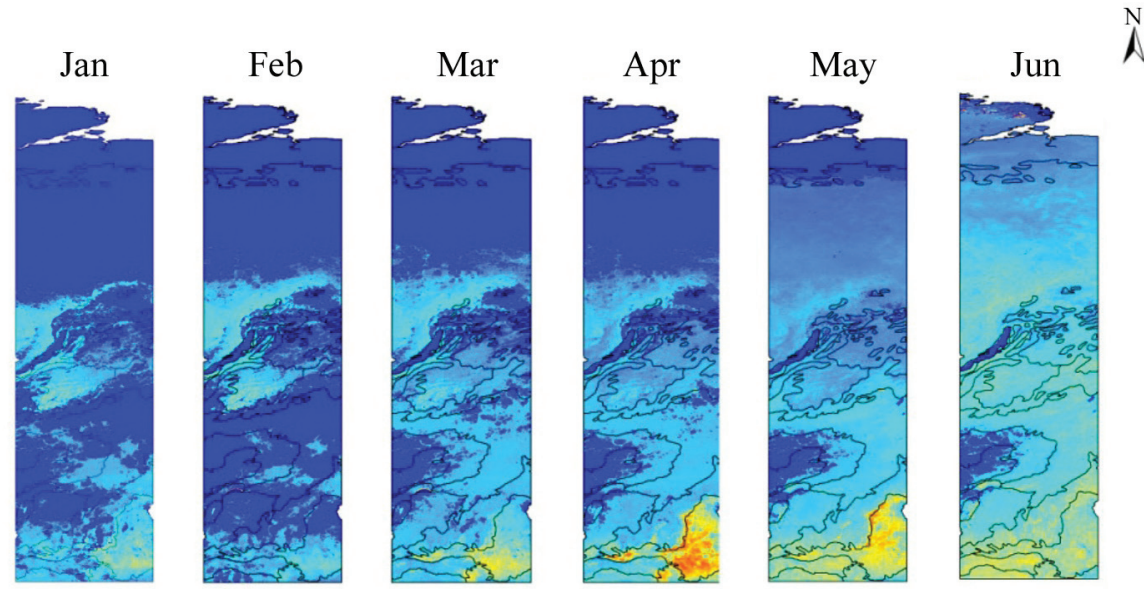

$\stackrel{N}{\Lambda}$
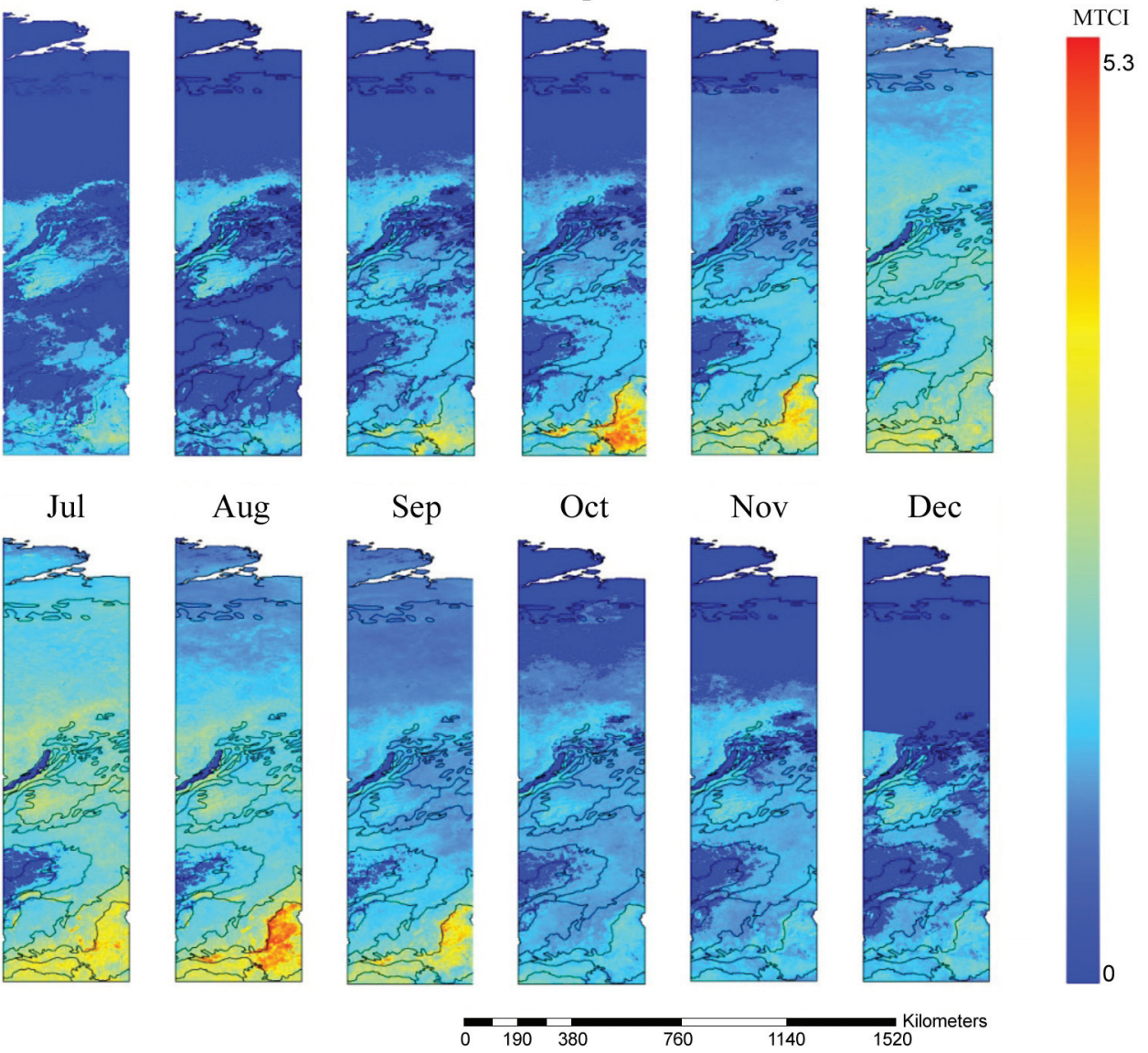

1520

Fig. 5. Spatio-temporal variations in (a) multi-year monthly average MTCI and (b) annual average MTCI profile across NSTNEA. 
(b)

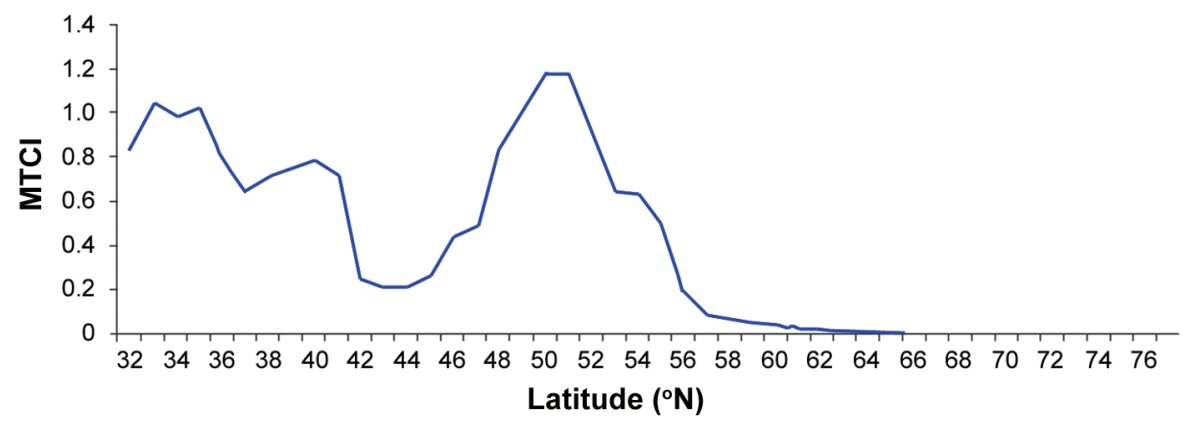

Fig. 5. (Continued)

the chlorophyll content showed a gradually decreasing trend from south to north except in the semi-desert region. For the NSTNEA, the chlorophyll content was lowest in winter, then, rose with increasing temperature until August. With the advent of autumn, the chlorophyll content of vegetation came down to a low value. However, vegetation types play an important role for seasonal variation. Different types of vegetation showed obvious discrepancies in seasonal characteristics. For example, the forests in mid latitudes manifested high chlorophyll contents from April to September, while tundra in high latitudes only showed the high value in summer.

To study the latitudinal variation in canopy chlorophyll content with temperature and precipitation gradient across the NSTNEA, first, the multi-year average values for MTCI were estimated for each pixel for the five years of the study period. Then, the average MTCI was estimated for $1^{\circ}$ increments of latitude within the transect. Figure $5 \mathrm{~b}$ shows that the chlorophyll presented an obvious fluctuation with latitude. With the presence of high temperatures in the south, the first MTCI peak appeared at ca $34^{\circ} \mathrm{N}$ where the main vegetation was evergreen forest and the second peak emerged at $40^{\circ} \mathrm{N}$ due to the distribution of mixed and conifer forests. In the semi-desert with little precipitation, a valley value appeared at $44^{\circ} \mathrm{N}$. The last peak of chlorophyll occurred at ca $51^{\circ} \mathrm{N}$ with conifer forest ecoregions, then the chlorophyll content dropped sharply until $60^{\circ} \mathrm{N}$ with decreasing temperature.

\subsection{Phenological Analysis}

In the section, we quantitatively describe the phenological characteristics of ecoregions in our transect and attempt to illustrate the diversity due to latitudinal variation in temperature and precipitation across Northeast Asia. The overall phenological variation for all ecoregions in NSTNEA during the four complete growing seasons is shown in Fig. 6. Figure 6 represents the eight major phenological vari- ables plotted against the latitude of ecoregions. They were derived from the smoothed MTCI curves, and accumulated to show the phenogoical overall status for ecoregions during the study period. In Figs. $6 \mathrm{a}-\mathrm{f}$, the numbers in the boxes represent the compositing periods, and in Figs. $6 \mathrm{~g}-\mathrm{h}$ they represent the MTCI values.

At lower latitudes for all four years, the onset of greenness was earlier than for the higher latitudes (Fig. 6a). Exceptions to this trend were observed in some ecoregions (PA0401, PA0804 and PA0813). At mid latitudes (less than $40^{\circ}$ ), the onset of greenness in 2003 was later than for other years for most ecoregions. This can be explained by the extreme snow during the winter of 2003 (from December 2002 to February 2003) experienced in north China (http:// www.china.com.cn/). The vegetation types in high latitudes showed a similar onset of greenness mainly due to the low temperature, although their chlorophyll contents showed discrepancy with each other. For EndP, those of ecoregions at high latitudes were earlier than those at mid latitudes, but there was no obvious gradient feature along the NSTNEA. Figure $6 \mathrm{c}$ shows the duration of greenness of ecoregions across the NSTNEA. In general, the length of season at high latitudes was shorter than at mid latitudes. The average length of season was detected around composting periods 22 between $32^{\circ}$ to $47^{\circ}$ latitude and above this latitude the length of season was detected nearly 10 composting periods shorter. The longest length of season was detected in PA0813, followed by PA0424 and PA0415. The ecoregions around $44^{\circ} \mathrm{N}$ appeared to have a shorter growing season resulting from a lack of rainfall, while the East Siberian taiga and Trans-Baikal Bald Mountain tundra presented a longer growing season than other regions in the high latitudes. This resulted from abundant precipitation in this region, indicating that besides temperature, precipitation also promoted an increase in growth duration to some extent.

For the time of maximum MTCI shown as Fig. 6d, the latitudinal variation was less pronounced than that for onset of greenness. During the study period, the average MaxP 
was detected around composting period 25 (ca. in late June) for most ecoregions. Exceptions were observed in PA0415 (Changjiang Plain evergreen forests) and PA0424 (Huang He Plain mixed forests), which were much earlier than other ecoregions. Because of drought, the Eastern Gobi desert steppe was the latest to reach the MTCI peak. Considering the DurUp, those at mid latitude were longer than those at high latitudes. The same applies to DurDn. The patterns were similar to those of the DurP which was influenced both by temperature and precipitation. The above mentioned indicates that although precipitation plays a promoting role temperature is still the dominant factor in vegetation phenological period.

Figure $6 \mathrm{~g}$ shows the maximum MTCI value of ecoregions in NSTNEA. The average MaxV of forest was 2.4, followed by steppe and grassland with 1.7, and the lowest average $\mathrm{Max} V$ was detected in tundra, only 1.3 during last five years. It indicates that the $\mathrm{Max} V$ was significantly correlated with vegetation types. The evergreen and mixed forest ecoregions at mid latitudes showed the highest chlorophyll content followed by conifer forest and forest steppe in mid-high latitudes. The conifer forest and grassland around $44^{\circ} \mathrm{N}$ showed lower maximum chlorophyll content due to water deficiency, especially in the Alashan Plateau semidesert and Eastern Gobi desert steppe. The MaxV of the Taimyr-Central Siberian tundra was the lowest because of the temperature restriction. For RanV, correlated with vegetation function type, there was a declining trend with an increase in latitude. However, for the East Siberian taiga and Trans-Baikal Bald Mountain tundra, the RanV appeared significantly larger than that of other ecoregions at high latitudes due to abundant precipitation. The Alashan Plateau semi-desert and Eastern Gobi desert steppe still showed a lower RanV because of the constraint of available water.

\subsection{The Cumulative Coefficient of Variation on Pheno- logical Metrics}

The coefficient of variation (CV) could characterize the fluctuation intensity of the subject investigated. Therefore, the $\mathrm{CV}$ of phenology metrics could be used to indicate the activity or instability of different vegetation types along the temperature and precipitation gradient in mid and high latitudes. We calculated and accumulated the $\mathrm{CV}$ of each (a)

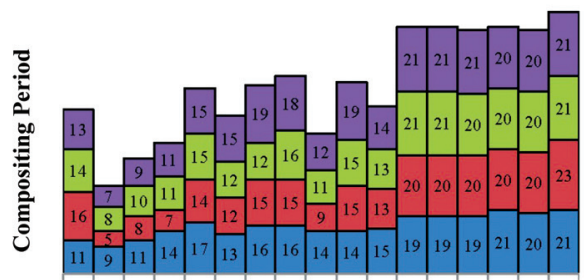

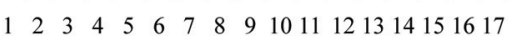

(d)

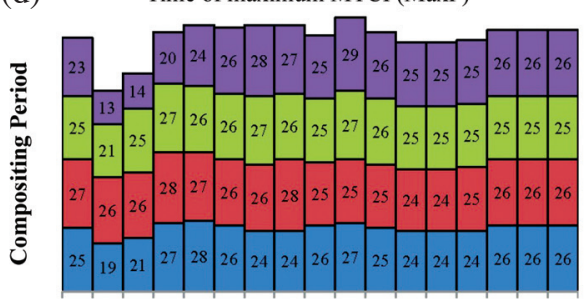

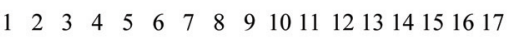

Maximum MTCI value (MaxV)

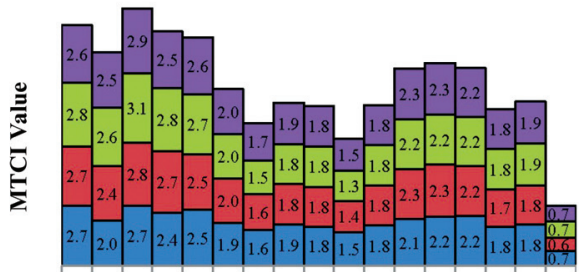

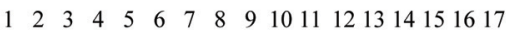

(b)

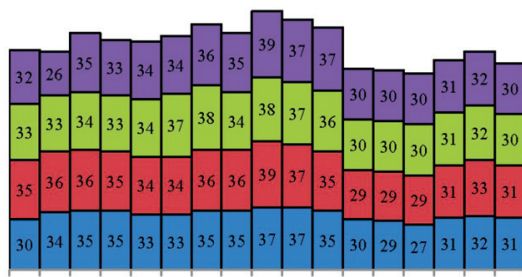

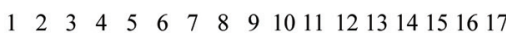

(e)

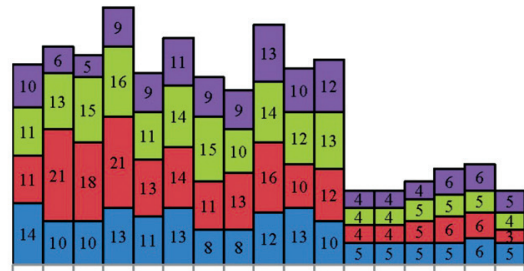

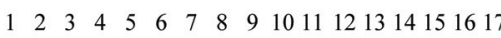

(h)

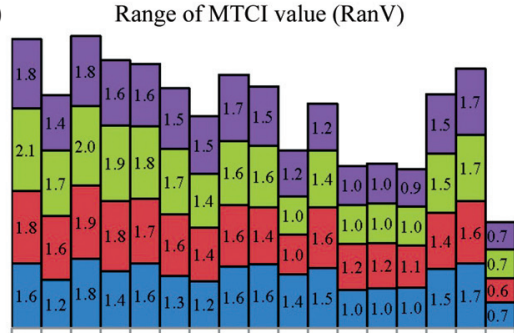

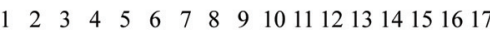

(c)

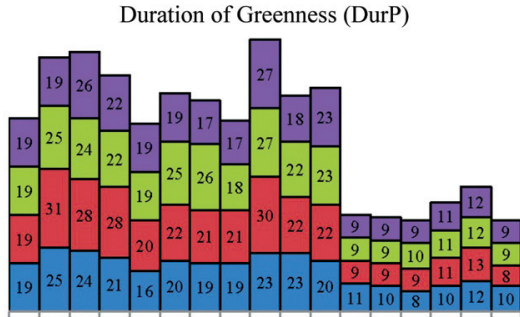

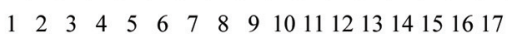

Duration of senescence (DurDn)

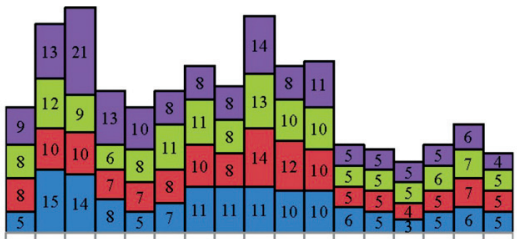

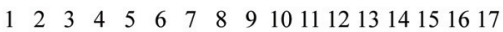

Fig. 6. Phenological variations of ecoregions arranged by latitude (x-axis: number of ecoregions in Table 1) from 2003 to 2007. The numbers in the boxes represent the compositing periods in (a) - (f), and represent the MTCI values in (g) - (h). 
phenology metric according to ecoregions during the four integrated growing seasons, then arranged them by latitude (Fig. 7). The finding showed that the cumulative CV showed a declining trend with an increase in latitude overall. It indicated that temperature is the determining factor on the activity of vegetation growth in Northeast Asia. Furthermore, vegetation type also affected the fluctuation intensity of the phenology metrics. For forest ecoregions, the cumulative CVs of phenology metrics were relatively higher, even if in the region above $50^{\circ} \mathrm{N}$, Trans-Baikal conifer forests and Sayan montane conifer forests still showed higher cumulative CVs than other vegetation types in similar latitudes. However, the Alashan Plateau semi-desert and Eastern Gobi desert steppe also presented relatively high cumulative CVs of phenology metrics. The reason may be that the growth of vegetation in these ecoregions was restricted with regard to moisture conditions, so the phenology characteristics were significantly sensitive to precipitation which showed obvious inter-annual differences. In addition, the cumulative CV of Taimyr-Central Siberian tundra showed notable higher than other ecoregions in high latitude. This may be explained by the influence of snow cover and melt resulting in inaccurate monitoring of vegetation growth periods.

\section{DISCUSSION}

For the first time, this study attempted to establish a broad regional phenological pattern for Northeast Asia using a remotely sensed estimation of canopy chlorophyll content data over five years. Though this is a short time period, the method used in the study could provide a valuable data set to study the effect of climate change on the phenological pattern of natural vegetation in Northeast Asia in the longer term.

The phenological patterns detected from this study for natural vegetation of ecoregions broadly match earlier studies (Tucker et al. 2001; Zhang et al. 2004; De Beurs and Henebry 2005). Expected phenological pattern for major vegetation types was observed. In particular, the expected trend in latitudinal variability of key phenological variables was observed. The onset of greenness for most natural vegetation followed a latitudinal pattern with earlier onset of greenness at lower latitudes (Fig. 6a). In high latitude regions, there was a large leafless period for most vegetation types (Elliott et al. 2006). In general, the length of growing season was higher at lower latitudes. Additionally, for forests in NSTNEA, the average maximum MTCI value was 2.6 between 32 and $35^{\circ} \mathrm{N}$, while that was detected as 2.2 between 48 and $54^{\circ} \mathrm{N}$ during the study period. Similar trend was observed for a range of MTCI values.

In Northeast Asia, several studies were undertaken to characterize vegetation phenology (Tucker et al. 2001; De Beurs and Henebry 2005). However, most of these studies provided phenological information at a coarse temporal resolution (mainly monthly). The availability of near real-time weekly and global MTCI composites (Curran et al. 2007) enables researchers to extract phonological variables accurately. In addition, the MTCI has the advantage over some remotely sensed products such as the Moderate Resolution Imaging Spectroradiometer (MODIS) NDVI, because the images of MTCI cover the whole Arctic region throughout the year.

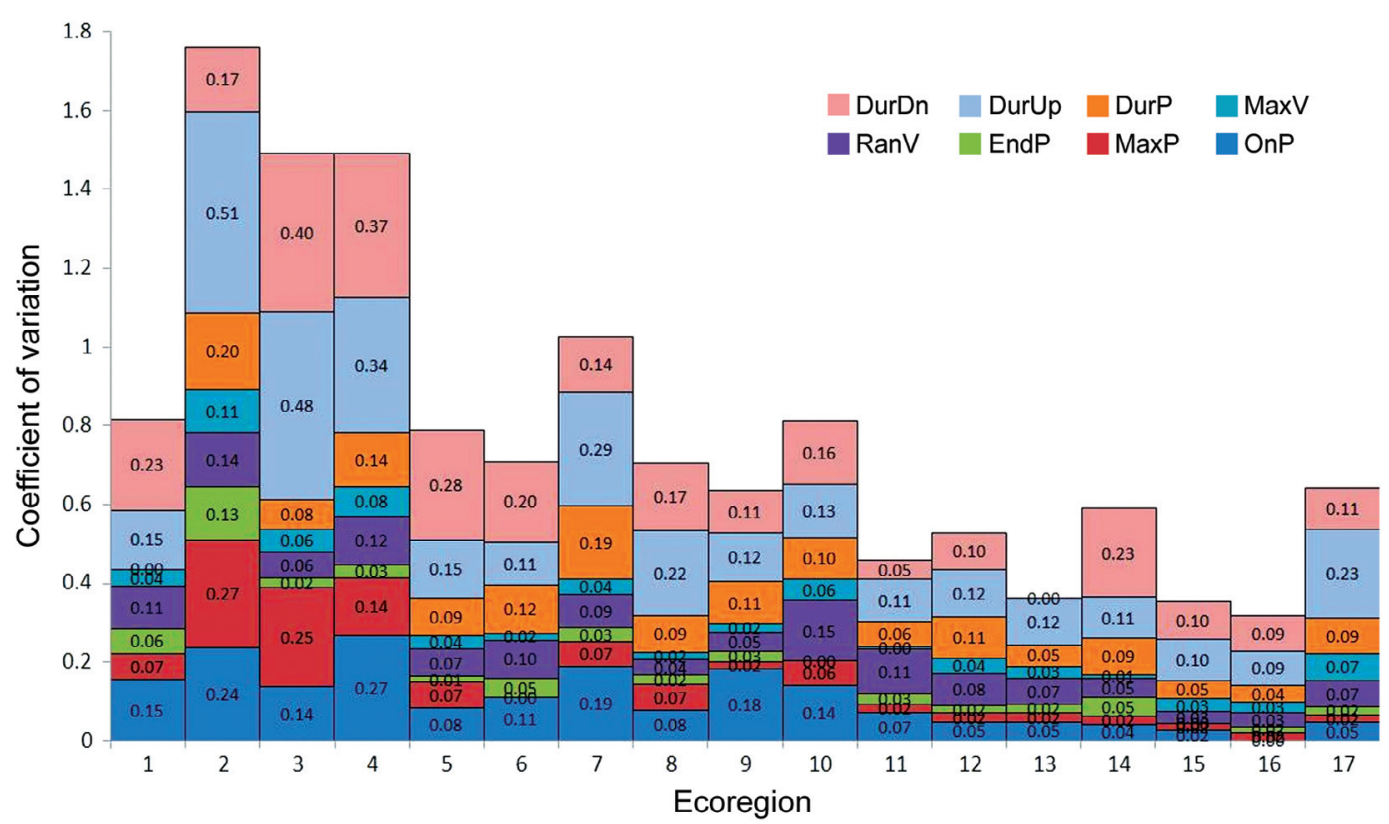

Fig. 7. The cumulative coefficient of variation of phenological metrics (x-axis: number of ecoregions in Table 1) for each ecoregion from 2003 to 2007. The numbers in the boxes represent the coefficient of variation. 


\section{CONCLUSION}

This study detects a suite of phenological variables of ecoregions for the North-South Transect of Northeast Asia using multi-temporal composites of a remote sensingbased chlorophyll index. The asymmetric Gaussian model was used to smooth the MTCI signal while maintaining the overall phenological pattern for the years 2003 to 2007 . The major ecoregions in Northeast Asia were obtained from the WWF Terrestrial Ecoregions map.

In this study, spatial variation with latitude was observed for the chlorophyll content and phenological variables for natural vegetation across NSTNEA. The expected trend in latitudinal variability of phenological pattern was observed. The onset of greenness for most ecoregions followed a latitudinal pattern with earlier onset of greenness at lower latitudes. In general, the length of growing season was higher at lower latitudes. For forests in NSTNEA, the average maximum MTCI value and range of MTCI value at lower latitudes were significantly larger than that at higher latitudes during the study period. In addition, the cumulative $\mathrm{CV}$ showed a declining trend with an increase in latitude overall. Our findings suggest that although precipitation plays a promoting role, temperature is still the dominant factor in vegetation phenological period at high latitudes.

Acknowledgements Funding support partially from the NSF China Major Program (61190114) and the State Key Fundamental Science Funds of China (2011CB302705, 2011CB302705, 2010CB950702 and 2010CB428503), NSFChina Project (41171324, 40671132 and 30590383), the Funds for Ph.D. Education (20110091110028), the State Key Basic Research Funds of China (2007FY110300-04 and 08), the key project of Zhejiang Province (2008C13G2100010), the State High Technology Funds of China (2009AA122001 and 2009AA122005), State Key International Cooperation Project (20073819), the Project Funded by the Priority Academic Program Development of Jiangsu Higher Education Institutions, Zhejiang province key science and technology innovation team (2010R50030).

\section{REFERENCES}

Berberoglu, S., F. Evrendilek, C. Ozkan, and C. Donmez, 2007: Modeling forest productivity using Envisat MERIS data. Sensors, 7, 2115-2127, doi: 10.3390/S71 02115. [Link]

Bradley, R. S., F. T. Keiming, and H. F. Diaz, 1993: Recent changes in the North American Arctic boundary layer in winter. J. Geophys. Res., 98, 8851-8858, doi: 10.1029/93JD00311. [Link]

Canadell, J. G., H. A. Mooney, D. D. Baldocchi, J. A. Berry, J. R. Ehleringer, C. B. Field, S. T. Gower, D. Y. Hollinger, J. E. Hunt, R. B. Jackson, S. W. Running, G. R. Shaver, W. Steffen, S. E. Trumbore, R. Valentini, and
B. Y. Bond, 2000: Commentary: Carbon metabolism of the terrestrial biosphere: A multitechnique approach for improved understanding. Ecosystems, 3, 115-130, doi: 10.1007/s100210000014. [Link]

Canadell, J. G., W. L. Steffen, and P. S. White, 2002: IGBP/GCTE terrestrial transects: Dynamics of terrestrial ecosystems under environmental change. J. Veg. Sci., 13, 298-300, doi: 10.1111/j.1654-1103.2002.tb02 054.x. [Link]

Chapin III, F. S., A. D. Mcguire, J. Randerson, R. Pielke Sr., D. Baldocchi, S. E. Hobbie, N. Roulet, W. Eugster, E. Kasischke, E. B. Rastetter, S. A. Zimov, and S. W. Running, 2000: Arctic and boreal ecosystems of western North America as components of the climate system. Global Change Biol., 6, 211-223, doi: 10.1046/j.1365-2486.2000.06022.x. [Link]

Chase, T. N., R. A. Pielke Sr., J. A. Knaff, T. G. F. Kittel, and J. L. Eastman, 2000: A comparison of regional trends in 1979-1997 depth-averaged tropospheric temperatures. Int. J. Climatol., 20, 503-518, doi: 10.1002/ (SICI)1097-0088(200004)20:5<503::AID-JOC491> 3.0.CO;2-0. [Link]

Curran, P. J. and C. M. Steele, 2005: MERIS: The re-branding of an ocean sensor. Int. J. Remote Sens., 26, 17811798, doi: 10.1080/01431160412331330275. [Link]

Curran, P. J., J. Dash, and G. M. Llewellyn, 2007: Indian Ocean tsunami: The use of MERIS (MTCI) data to infer salt stress in coastal vegetation. Int. J. Remote Sens., 28, 729-735, doi: 10.1080/01431160600821093. [Link]

Dash, J. and P. J. Curran, 2007: Evaluation of the MERIS terrestrial chlorophyll index (MTCI). Adv. Space Res., 39, 100-104, doi: 10.1016/j.asr.2006.02.034. [Link]

Dash, J., T. Lankester, S. Hubbard, and P. J. Curran, 2008: Signal-to-noise ratio for MTCI and NDVI time series data. Proceeding of the $2^{\text {nd }}$ MERIS/(A)ATSR User Workshop, Frascati, Italy, 22-26 September 2008 (ESA SP-666).

Dash, J., C. Jeganathan, and P. M. Atkinson, 2010: The use of MERIS Terrestrial Chlorophyll Index to study spatio-temporal variation in vegetation phenology over India. Remote Sens. Environ., 114, 1388-1402, doi: 10.1016/j.rse.2010.01.021. [Link]

De Beurs, K. M. and G. M. Henebry, 2005: Land surface phenology and temperature variation in the International Geosphere-Biosphere Program high-latitude transects. Global Change Biol., 11, 779-790, doi: 10.11 11/j.1365-2486.2005.00949.x. [Link]

Edwards, M. and A. J. Richardson, 2004: Impact of climate change on marine pelagic phenology and trophic mismatch. Nature, 430, 881-884, doi: 10.1038/nature 02808. [Link]

Epstein,H.E., M.D. Walker,F.S.Chapin III, and A. M. Starfield, 2000: A transient, nutrient-based model of arctic plant community response to climatic warming. Ecol. 
Appl., 10, 824-841, doi: 10.1890/1051-0761(2000)010 [0824:ATNBMO]2.0.CO;2. [Link]

España-Boquera, M. L., R. Cárdenas-Navarro, L. LópezPérez, V. Castellanos-Morales, and P. Lobit, 2006: Estimating the nitrogen concentration of strawberry plants from its spectral response. Commun. Soil Sci. Plant Anal., 37, 2447-2459, doi: 10.1080/001036206008200 97. [Link]

Goward, S. N., B. Markham, D. G. Dye, W. Dulaney, and J. Yang, 1991: Normalized difference vegetation index measurements from the advanced very high resolution radiometer. Remote Sens. Environ., 35, 257-277, doi: 10.1016/0034-4257(91)90017-Z. [Link]

Groisman, P. Y., R. W. Knight, V.N. Razuvaev, O. N. Bulygina, and T. R. Karl, 2006: State of the ground: Climatology and changes during the past 69 years over Northern Eurasia for a rarely used measure of snow cover and frozen land. J. Climate, 19, 4933-4955, doi: 10.11 75/JCLI3925.1. [Link]

Gutman, G. G., A. M. Ignatov, and S. Olson, 1994: Towards better quality of AVHRR composite images over land: Reduction of cloud contamination. Remote Sens. Environ., 50, 134-148, doi: 10.1016/0034-4257(94)90040X. [Link]

Hinzman, L., N. Bettez, W. Bolton, F. Chapin, M. Dyurgerov, C. Fastie, B. Griffith, R. Hollister, A. Hope, H. Huntington, A. Jensen, G. Jia, T. Jorgenson, D. Kane, DD. Klein, G. Kofinas, A. Lynch, A. Lloyd, A. McGuire, F. Nelson, W. Oechel, T. Osterkamp, C. Racine, V. Romanovsky, R. Stone, D. Stow, M. Sturm, C. Tweedie, G. Vourlitis, M. Walker, D. Walker, P. Webber, J. Welker, K. Winker, and K. Yoshikawa, 2005: Evidence and implications of recent climate change in Northern Alaska and other Arctic regions. Clim. Change, 72, 251-298, doi: 10.1007/s10584-0055352-2. [Link]

Hofgaard, A., 1997: Structural changes in the forest-tundra ecotone: A dynamic process. In: Huntley, B., W. Cramer, A. V. Morgan, H. C. Prentice, and J. R. M. Allen (Eds.), Past and Future Rapid Environmental Changes: The Spatial and Evolutionary Responses of Terrestrial Biota, Springer Verlag, Berlin, 255-263.

Huete, A., K. Didan, T. Miura, E. P. Rodriguez, X. Gao, and L. G. Ferreira, 2002: Overview of the radiometric and biophysical performance of the MODIS vegetation indices. Remote Sens. Environ., 83, 195-213, doi: 10.1016/S0034-4257(02)00096-2. [Link]

IPCC (Intergovernmental Panel on Climate Change), 2001a: Climate change 2001: Impacts, adaptation, and vulnerability. In: McCarthy, J. J., O. F. Canziani, N. A. Leary, D. J. Dokken, K. S White, (Eds.), Contribution of Working Group II to the Third Assessment Report of the Intergovernmental Panel on Climate Change, Cambridge University Press, 1032.
IPCC (Intergovernmental Panel on Climate Change), 2001b: Climate change 2001: Synthesis report. In: Watson, R. T. and the CoreWriting Team (Eds.), A Contribution of Working Groups I, II, and III to the Third Assessment Report of the Intergovernmental Panel on Climate Change, Cambridge University Press, 398.

Jeganathan, C., J. Dash, and P. M. Atkinson, 2010: Mapping the phenology of natural vegetation in India using a remote sensing-derived chlorophyll index. Int J. Remote Sens., 31, 5777-5796, doi: 10.1080/014311 61.2010.512303. [Link]

Jia, G. J., H. E. Epstein, and D. A. Walker, 2002: Spatial characteristics of AVHRR-NDVI along latitudinal transects in northern Alaska. J. Veg. Sci., 13, 315-326, doi: 10.1111/j.1654-1103.2002.tb02056.x. [Link]

Jönsson, P. and L. Eklundh, 2002: Seasonality extraction by function fitting to time-series of satellite sensor data. IEEE Trans. Geosci. Remote Sensing, 40, 1824-1832, doi: 10.1109/TGRS.2002.802519. [Link]

Jönsson, P. and L. Eklundh, 2004: TIMESAT- A program for analyzing time-series of satellite sensor data. Comput. Geosci., 30, 833-845, doi: 10.1016/j.cageo.2004.05.00 6. [Link]

Koch, G. W., R. J. Scholes, W. L. Steffen, P. M. Vitousek, and B. H. Wakler, 1995: The IGBP terrestrial transects: Science plan. The International Geosphere-Biosphere Programme, Report No. 36, Stockholm, SE, 5-7.

McGuire, A. D. and J. E. Hobbie, 1997: Global climate change and the equilibrium responses of carbon storage in arctic and subarctic regions. In: Modeling the Arctic System: A Workshop Report on the State of Modeling in the Arctic System Science Program, from the ARCSS Modeling Workshop, 15-16 January 1996, Boulder, Colorado, The Arctic Research Consortium of the United States, Fairbanks, AK, 53-54.

McGuire, A. D., J. S. Clein, J. M. Melillo, D. W. Kicklighter, R. A. Meier, C. J. Vorosmarty, and M. C. Serreze, 2000: Modelling carbon responses of tundra ecosystems to historical and projected climate: Sensitivity of pan-Arctic carbon storage to temporal and spatial variation in climate. Global Change Biol., 6, 141-159, doi: 10.1046/j.1365-2486.2000.06017.x. [Link]

Mutanga, O. and A. K. Skidmore, 2004: Narrow band vegetation indices overcome the saturation problem in biomass estimation. Int. J. Remote Sens., 25, 3999-4014, doi: 10.1080/01431160310001654923. [Link]

Reed, B. C., J. F. Brown, D. VanderZee, T. R. Loveland, J. W. Merchant, and D. O. Ohlen, 1994: Measuring phenological variability from satellite imagery. J. Veg. Sci., 5, 703-714, doi: 10.2307/3235884. [Link]

Rosenqvist, A., M. Imhoff, A. Milne, and C. Dobson, 2000: Remote sensing and the Kyoto protocol - A workshop summary. Int. Archi. Photogram. Remote Sens., XXXIII, 1278-1285. 
Tucker, C. J., D. A. Slayback, J. E. Pinzon, S. O. Los, R. B. Myneni, and M. G. Taylor, 2001: Higher northern latitude normalized difference vegetation index and growing season trends from 1982 to 1999. Int. J. Biometeorol., 45, 184-190, doi: 10.1007/s00484-001-0109-8. [Link]

Yu, F., K. P. Price, J. Ellis, and P. Shi, 2003: Response of seasonal vegetation development to climatic variations in eastern central Asia. Remote Sens. Environ., 87, 4254, doi: 10.1016/S0034-4257(03)00144-5. [Link]
Zhang, X., M. A. Friedl, C. B. Schaaf, and A. H. Strahler, 2004: Climate controls on vegetation phenological patterns in northern mid- and high latitudes inferred from MODIS data. Global Change Biol., 10, 1133-1145, doi: 10.1111/j.1529-8817.2003.00784.x. [Link]

Zhang, Y., J. M. Chen, J. R. Miller, and T. L. Noland, 2008: Leaf chlorophyll content retrieval from airborne hyperspectral remote sensing imagery. Remote Sens. Environ., 112, 3234-3247, doi: 10.1016/j.rse.2008.04.005. [Link] 